\title{
The Help-Seeking Process in Same-Sex Intimate Partner Violence: a Systematic Review
}

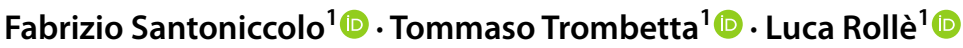

Accepted: 26 July 2021 / Published online: 15 August 2021

(c) The Author(s) 2021

\begin{abstract}
Introduction Same-Sex Intimate Partner Violence (SSIPV) is a complex issue that can be severely damaging. When involved in SSIPV, victims and perpetrators sometimes choose to seek help. The help-seeking process, however, can be difficult. Experiences of help-seeking seem to vary and may be positive or negative depending on several factors, some of which appear to be specific to lesbian, gay, and bisexual (LGB) people involved in a same-sex relationship.

Methods A systematic review of the literature has been conducted across four databases following the PRISMA statement guidelines. Out of 410 screened abstracts, 78 articles were selected for full-text review. Following the inclusion and exclusion criteria, 21 studies were included in the current review. Thematic analysis was conducted on these studies and results were discussed by three reviewers.

Results Help-seekers tended to use informal sources of help, perceived to be ambivalently helpful. Formal sources tended to be utilized sparingly, except for counselors. Many formal sources were perceived to be unhelpful, and most of the studies identified several barriers to services that prevented effective help. Formal and helpful sources were perceived as knowledgeable and sensitive about LGB themes.

Conclusions While existing research is limited, formal services that can provide effective care for SSIPV appear scarce. Barriers to services seem widespread, limiting accessibility.

Policy Implications Existing services would benefit from increasing their knowledge and sensitivity on SSIPV-specific themes. The development of policies, programs, and interventions that aim to provide effective help is needed, as well as more research.
\end{abstract}

Keywords Intimate partner violence $\cdot$ Help-seeking $\cdot$ Same-sex $\cdot$ Same-gender $\cdot$ Gay $\cdot$ Lesbian $\cdot$ LGB $\cdot$ Same-sex intimate partner violence

\section{Introduction}

Intimate Partner Violence (IPV) refers to the occurrence of a vast array of violent behaviors in an intimate relationship, such as physical, psychological, sexual, and economic violence as well as stalking (American Psychological Association, 2012). The consequences of being exposed to these couple dynamics can range from damaging to life-threatening, with survivors often displaying numerous negative effects, both physical and mental (Randle \& Graham, 2011; World Health Organization, 2013).

Tommaso Trombetta

tommaso.trombetta@unito.it

1 Department of Psychology, University of Turin, Via Verdi 10, 10124 Torino, Italy
People involved in violent couple dynamics may initiate a process of help-seeking in which they resort to external sources (e.g., friends, family, shelters, clinicians, police officers) in order to either resolve the situation, find ways to improve it or recover their mental and physical health. Among the many factors shaping victims' and perpetrators' experience of couple violence and the help-seeking process, sexual orientation seems to play a crucial role in several key aspects (Rollè, et al., 2021), such as perceiving the violence as a problem, selecting a source of help, and deciding whether to seek help at all.

In general, a victim's willingness to seek help may be affected by their evaluation of the problem, their interactions with their social circle and community, previous experiences, expectations of support and the existence of services that cater to their specific needs. In their conceptual 
framework for understanding these processes, Liang et al. (2005) identify three non-linear stages of help-seeking: problem recognition and definition, decision to seek help and support selection. They identify three levels of influence on the process as a whole: individual, interpersonal, and sociocultural.

The help-seeking process is not, in fact, characterized by a strict progression from one stage to the next and involves interaction between the stages. The involved subjects may also shape their decisions based on feedback from other stages and influences (e.g., they may base their decision to seek help based on their previous help-seeking experiences or change their definition of the issue based on feedback from selected sources) (Liang et al., 2005).

Gay men and lesbian women share a specific combination of factors that can discourage them from help-seeking or make the whole process less effective. For example, the fear inherent in IPV situations and their expectations (or previous experiences) of homonegativity may cause them to avoid seeking support, due to the chance of revictimization, producing feelings of isolation (Duke \& Davidson, 2009; Calton et al., 2015; Rollè, et al., 2021). They may fear casting a negative light on their sexual orientation as highlighted, for example, by Renzetti (1989) and Irwin (2006). A key role is played by the strong presence of heteronormativity in social contexts (Kitzinger, 2005; Warner, 1991), that is, "the assumption that heterosexuality is the standard for defining normal sexual behavior and that male-female differences and gender roles are the natural and immutable essentials in normal human relations" (American Psychological Association, 2020). A heteronormative conception of partner violence hinders the recognition of the problem in perpetrators, victims, and service providers as well, as IPV is often portrayed as a "gendered" problem (i.e., perpetrated by a man on a woman). Stereotypes linked to gender roles may influence beliefs about partner violence, such as believing gay men, women in general or lesbians specifically to be incapable of real violence or classifying it as a normal part of mutual arguments (Duke \& Davidson, 2009), assuming that a man is always a perpetrator and a woman is always a victim (Cannon, 2019), normalizing violence amongst gay men as a part of affirming masculinity (Potoczniak et al., 2003) or believing masculine-presenting lesbian women to be more likely to perpetrate violence (Hassouneh \& Glass, 2008).

In both media representation (Estes \& Webber, 2021; Rollè et al., 2020) and scientific research (Sylaska \& Edwards, 2015), the coverage of IPV has been overwhelmingly focused on heterosexual couples. Despite a comparatively lower number of studies, research on Same-Sex Intimate Partner Violence (SSIPV) has often estimated its prevalence to be at least as high, if not higher than the estimated prevalence in heterosexual couples, as summarized by Rollè et al. $(2018,2019)$ review of the literature. For example, Walters, et al. (2013) estimated the lifetime prevalence rate in a sample representative of the population of the USA of some forms of SSIPV (physical violence, sexual violence, and stalking) as $43.8 \%$ in lesbians and $26 \%$ in gay men. Craft et al. (2008) estimated the lifetime perpetration rate for psychological aggression to be as high as $97.4 \%$ (lesbians) and $93.5 \%$ (gay men), while perpetration rate for "at least once in the past year" was estimated as $65.2 \%$ (gay men) and $56.1 \%$ (lesbian women). In the secondary data analysis conducted by Messinger (2011), respondents with a history of same-sex relationships were twice as likely to experience all forms of IPV when compared with heterosexual respondents.

Violence in same-sex couples seems to share several aspects with heterosexual IPV (HIPV): physical, psychological/emotional, sexual, and economic violence may take place, as individual forms or combined (Barrett, 2015); it may be perpetrated bidirectionally as well as asymmetrically (McClennen, 2005; Messinger, 2018); victims may be hesitant to leave or to seek help, and stay in abusive relationships with a partner due to emotional or financial dependency as well as feelings of love (Merrill \& Wolfe, 2000).

However, gay men and lesbian women face an additional set of unique challenges related to their sexual orientation when dealing with IPV, especially in the process of helpseeking. Violent couple dynamics can (and often do) remain hidden due to the private nature of the phenomenon and factors such as shame, fear of retaliation, fear of abandonment or social desirability: these aspects seem to be particularly true for gay men and lesbian women involved in violent couple dynamics, as they may feel "doubly-closeted" both in the stigma surrounding couple violence and the stigma surrounding their sexual orientation. The lack of meaningful representation of this phenomenon has made it effectively invisible for many of the involved subjects: victims, perpetrators, service providers and policy makers may struggle to recognize violent dynamics, and therefore be unprepared to mobilize the appropriate resources, reducing the probability that a help-seeking process will take place or successfully improve the situation (McClennen, 2005). As a result of these factors, victims of SSIPV may behave differently in their relationship with potential sources of help, such as when selecting informal sources of help (i.e., sources they have an informal relationship with, who may not have formal training) or formal sources of help (i.e., sources who have formal training at least somewhat related to providing help).

This systematic review of the literature will cover the helpseeking process in SSIPV, describing the ways gay and lesbian people attempt help-seeking, the barriers to services they tend to encounter, the factors associated with help-seeking, and the existing gaps in research on the topic.

The results can be useful to update formal and informal sources of help as well as policy makers on the specific 
dynamics of help-seeking in SSIPV and the most common issues they could face when dealing with the phenomenon: being more aware of the existence of the problem and of the frequent barriers and marginalization its victims face might prove invaluable in supporting them through their hardships. Awareness of the gendered frames of references, heteronormative conceptions, myths, and stereotypes may help recognize previously undetected violent situations. Finally, through the exploration of these themes, resources may be developed for people caught in situations involving SSIPV, who might gain a heightened alertness about violent dynamics and therefore be better prepared to face the issue.

\section{Methods}

\section{Sources and Research Strategy}

This review used the Preferred Reporting Items for Systematic Review and Meta-Analyses (PRISMA) statement (Moher et al., 2009). Two independent reviewers (FS and TT) conducted a search through different engines. The search engines included: EBSCO, filtered for academic articles across different databases (APA PsycInfo, CINAHL Complete, Family Studies Abstracts, Gender Studies Database, Race Relations Abstracts, Social Sciences Abstracts (H.W. Wilson), Sociology Source Ultimate, Violence \& Abuse Abstracts); Pubmed; SCOPUS; Web of Science. The following string was used across four different fields:

violence or abuse or aggression or batter* AND partner or couple* or domestic or intimate or dating or spouse AND

"same-sex" or "same-gender" or gay or lesbian* or bisex* or $\operatorname{lgb} *$ or homosexual* or " $\mathrm{m} * \mathrm{n}$ who ha* sex with $\mathrm{m}^{*} \mathrm{n}$ " or msm or "wom*n who ha* sex with wom*n" or wsw or " $m * n$ who ha* sex with $m^{*} n$ and wom*n" or msmw or "wom*n who ha* sex with wom*n and $\mathrm{m} * \mathrm{n}$ " or wswm or sexual minorit* or " $\mathrm{m} * \mathrm{n}$ who love m*n" or "wom*n who love wom*n" AND "help seek*" or "treatment seek*" or "treatment engage*" or "service utilization."

No temporal limits were imposed on the search, which included articles from the beginning of the databases (1989) up to March 2021.

\section{Inclusion and Exclusion Criteria}

The following inclusion criteria were used to select studies during the screening phase: a) pertaining to the help-seeking process in subjects (victims, perpetrators, and support providers) involved in intimate partner violence within a same-sex relationship; b) original research paper; c) full text available in the English language.

The following exclusion criteria were used to select or exclude studies during the screening and full-text review phases: a) studies whose participants included people without clearly specifying whether their experience of IPV pertained to a same-sex relationship or a heterosexual relationship; b) studies pertaining to IPV whose methods or results did not clearly differentiate between heterosexual and samesex IPV; c) meta-analyses and literature reviews.

Ambiguous abstracts and titles that potentially met these criteria were selected for full-text review. Papers that clearly did not meet these criteria (e.g., meta-analyses and reviews of the literature) were not reviewed in their full text form and were excluded during the screening phase.

\section{Study Selection and Data Extraction}

The search string returned a total of 183 academic articles on EBSCO, which were reduced to 94 after accounting for duplicates across the various databases. Of these, 35 articles were selected after the screening of title and abstract for full-text review. On Pubmed, the string returned a total of 43 results, of which 9 were selected. On Web of Science, the string returned a total of 78 results, of which 46 were selected. Finally, on SCOPUS, the string returned 37 results, of which 27 were selected.

The 117 selected articles were then manually screened for duplicates across the various search engines. A total of 78 articles were eligible for full-text review after removing these duplicates.

The two reviewers (FS and TT) independently analyzed the full text of the studies. After in-depth analysis and application of the inclusion and exclusion criteria, a final total of 21 studies were included in the systematic review. Disagreements between the reviewers were discussed with a third reviewer (LR) until unanimous agreement was reached.

Figure 1 summarizes the systematic review process (Page et al., 2021).

\section{Results}

\section{Methodological issues}

Violence as a phenomenon poses several methodological challenges to the researchers attempting to study it. In the included studies, the heterogeneity of the employed methods reflects this.

The authors of the studies themselves list a wide variety of limitations that should be kept in consideration, often detailing circumstances that pertain to their study's specific 
Fig. 1 Systematic review process

\section{Identification of studies via databases}

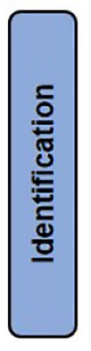

Records identified from*:

All databases $(n=341)$

EBSCO $(n=183)$

Pubmed $(n=43)$

Web of Science $(n=78)$

SCOPUS $(n=37)$
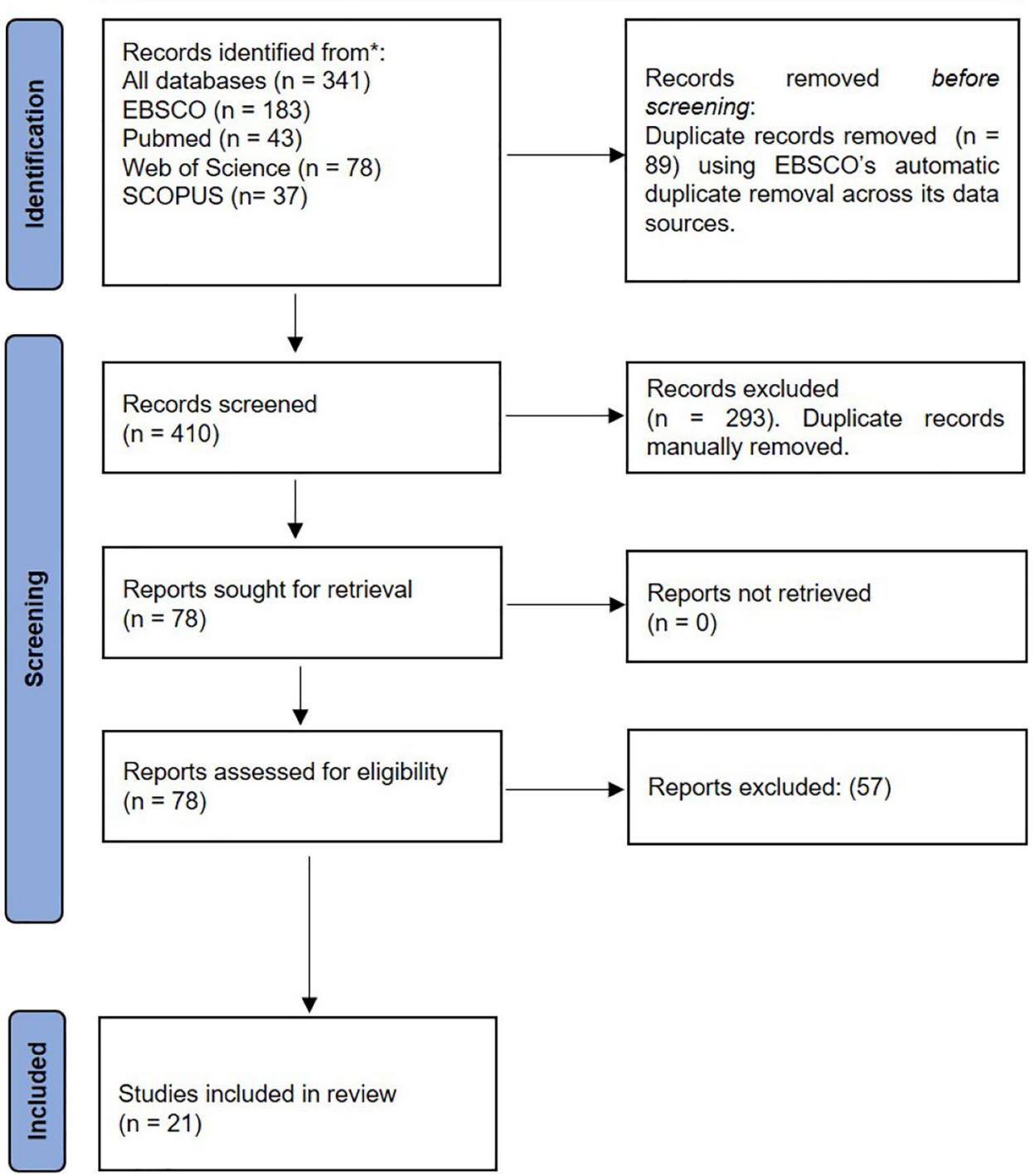

situation (Table 1). Common issues applying to multiple studies are featured prominently as well.

Studies that used qualitative methods (such as focus groups, semi-structured interviews, or one-on-one interviews) often used convenience sampling, and their samples were sometimes small and non-randomized: the ones in this review range from 4 (Walters, 2011) up to 40 (McDonald, 2012) people, some of them unbalanced in their composition in factors such as gender, education, or ethnicity (e.g., Scherzer, 1998; Walters, 2011). However, as previously discussed by Calton (2015), small sample sizes are to be expected when researching the intersection of two topics still rife with stigma: the intersection of stigmas related to sexual orientation and IPV severely limits the appeal of participation (Owen \& Burke, 2004; Walters, 2011), and restricts the viability of this participation to the respondents who are most comfortable (or motivated) about these two topics and who do not fear potentially stigmatizing environments.

The results in these studies stem primarily from qualitative analyses of conversations, open-ended questions, or discussions, which provide in-depth insight in the specific participants' experiences. Nevertheless, controlling for interference under these conditions may prove inherently difficult, and their generalizability may have suffered as a result.

On the other hand, the studies using quantitative methods produced more controlled results at the expense of scope, often investigating very specific research questions. These studies employed a wide range of tools. Many of them (Renzetti, 1989; Scherzer, 1998; Merrill \& Wolfe, 2000; St. Pierre \& Senn, 2010; Sylaska \& Edwards, 2015) 
Table 1 Methodologies

\begin{tabular}{|c|c|c|}
\hline Methodology & $N$ & Authors \\
\hline Questionnaires & 7 & $\begin{array}{l}\text { (Scherzer, 1998; Merrill \& Wolfe, 2000; McClennen et al., 2002; St. Pierre \& Senn, } 2010 \\
\text { Sylaska \& Edwards, 2015; Rausch, 2016; Di Battista et al., 2020) }\end{array}$ \\
\hline Semi-structured interviews & 5 & $\begin{array}{l}\text { (Hardesty et al., 2011; Walters, 2011; McDonald, 2012; Oliffe et al., 2014; Bloom et al., } \\
\text { 2015) }\end{array}$ \\
\hline Multi-method approaches & 4 & $\begin{array}{l}\text { (Renzetti, } 1989 \text { (surveys, unstructured interviews); Donovan \& Hester, } 2011 \text { (surveys, one } \\
\text { on one interviews, focus group discussions); Meza-de-Luna et al., } 2015 \text { (semi-structured } \\
\text { interviews, photo-interventions) Donovan \& Barnes, } 2020 \text { (surveys, semi-structured } \\
\text { interviews)) }\end{array}$ \\
\hline $\begin{array}{l}\text { Statistical analysis of pre-existing } \\
\text { dataset }\end{array}$ & 3 & (Guadalupe-Diaz, 2013; Ngo, 2018; Coston, 2019) \\
\hline Focus group discussions & 1 & (Freeland et al., 2018) \\
\hline Unstructured interviews & 1 & (Irwin, 2006) \\
\hline
\end{tabular}

used specially made, non-validated questionnaires, making it difficult to discern whether comparing their findings with other studies would produce meaningful insights. Some studies also modified pre-existing tools (McClennen et al., 2002; St. Pierre \& Senn, 2010) without attempting further validation. Comparing data obtained between such a heterogeneous set of tools may be statistically problematic.

Some shared methodological concerns are found in the general field of IPV research and may apply. The lack of a clear-cut definition of what constitutes violence and what does not may influence the participants' answers and their recognition of being involved in violent dynamics: participants may not know they are experiencing something that counts as IPV. This may be particularly true for the studies which employed self-report measures (e.g., the ad hoc questionnaires, or arguably the CTS2) with more discrete choices and no possibility of person-to-person discussion, and there is a chance that the experience of violence of many participants has gone undetected. When talking about more nuanced forms of violence (e.g., psychological or economic), this problem may be even more pronounced, as the participants' definitions of what counts as violence may be just as heterogeneous. Finally, the attempts to examine perpetrators and abusers as well may suffer from a heavy social desirability bias, and as such should not be taken at face value.

\section{Main Findings}

The included articles paint a wide and complex picture of the help-seeking process in SSIPV. Despite employing different methodologies and covering differing aspects of the phenomenon, their results often identify recurring themes in help-seeking experiences. Table 2 (see below) summarizes these findings.
Among most of the studies, numerous barriers to helpseeking are identified. Sixteen out of 21 studies recognized or mentioned some form of barrier to help-seeking (BTH).

Nine of the studies mentioned a heteronormative conception of IPV as an overarching theme that shapes the helpseeking process (HCI).

Fourteen of the studies described aspects of the helpseeking modes (HSM), such as the help-seekers' coping strategies and what kind of source they turn to.

Eight of the studies explained factors related to help-seeking (FRHS) in detail, i.e., factors that seemed to influence the chance of help-seeking.

Four of the studies recounted the help-seeking outcome (HSO), such as whether the person felt they received any help.

\section{Barriers to Help-Seeking}

In analyzing the barriers, the 15 studies rarely used a theoretical model, with 3 notable exceptions: Donovan and Barnes (2020) and Hardesty et al. (2011) who employed Liang et al. (2005) Barriers Model (three stages: problem recognition and definition, decision to seek help and support selection; three levels of influence: individual, interpersonal and sociocultural); St. Pierre and Senn (2010) who employed Grigsby and Hartman's (1997) Barriers Model (four layers: barriers in the environment, family and social role expectation, psychological consequences of abuse, childhood abuse and neglect issues). Nonetheless, the described barriers are consistent with these models' frameworks and would mostly fit their conceptualizations without significant adjustments. The two models, however, are both conceived with battered women in mind, and as such do not have a gender-neutral approach. While marginalization is taken into consideration as a barrier (Grigsby \& Hartman, 1997), its conceptualization is single-layered, and does not account for possible 


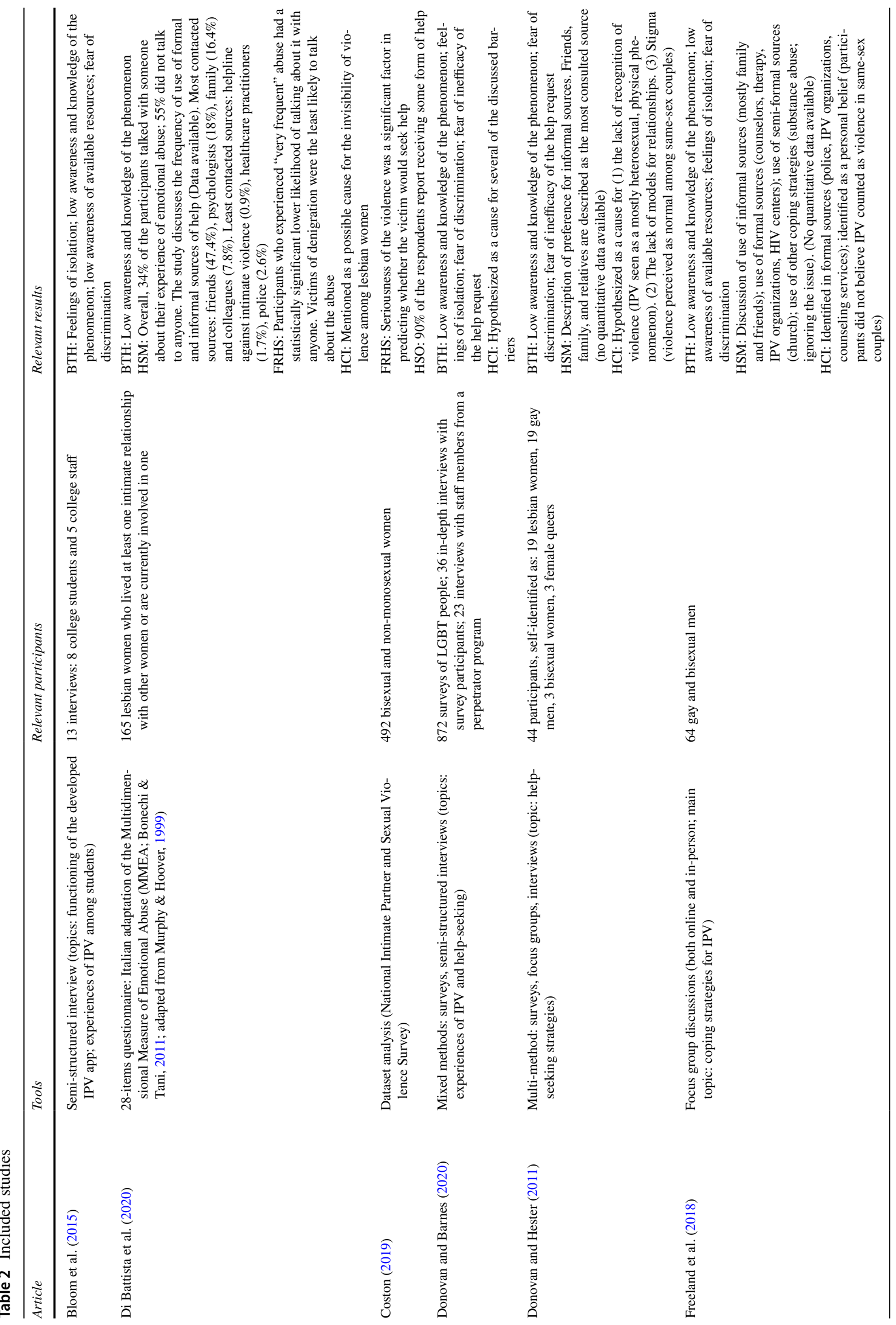




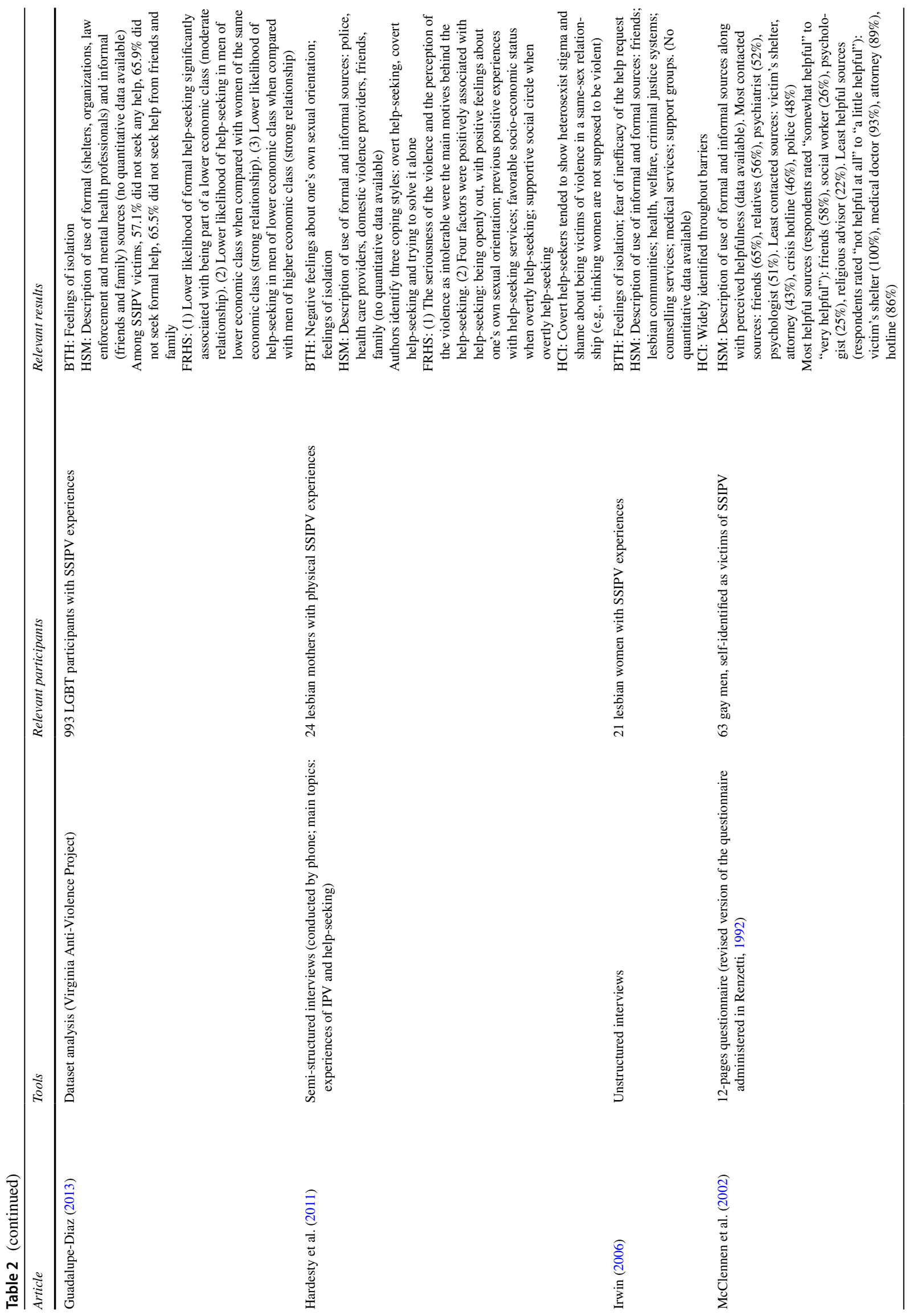




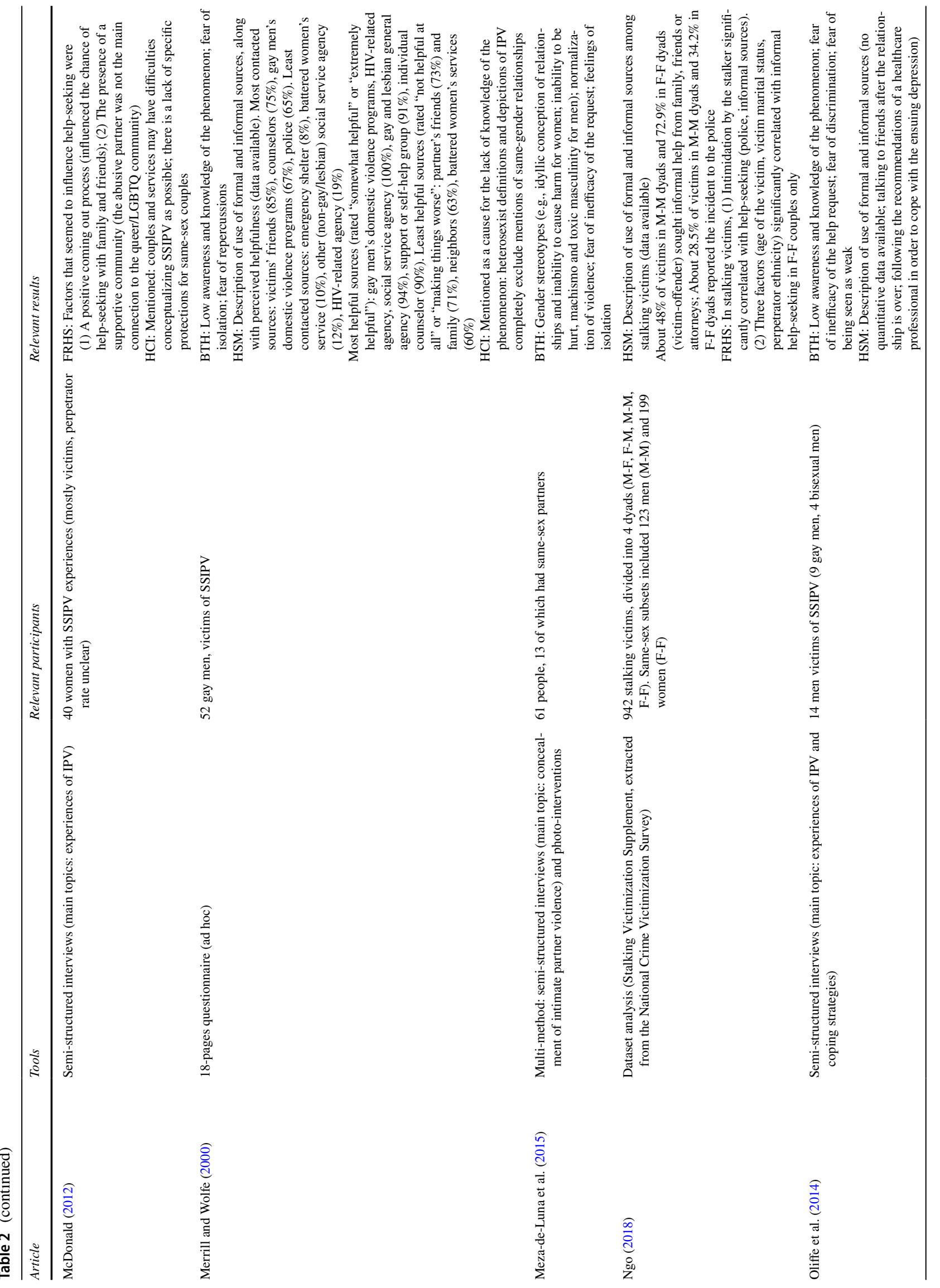


Sexuality Research and Social Policy (2021) 20:391-411

399

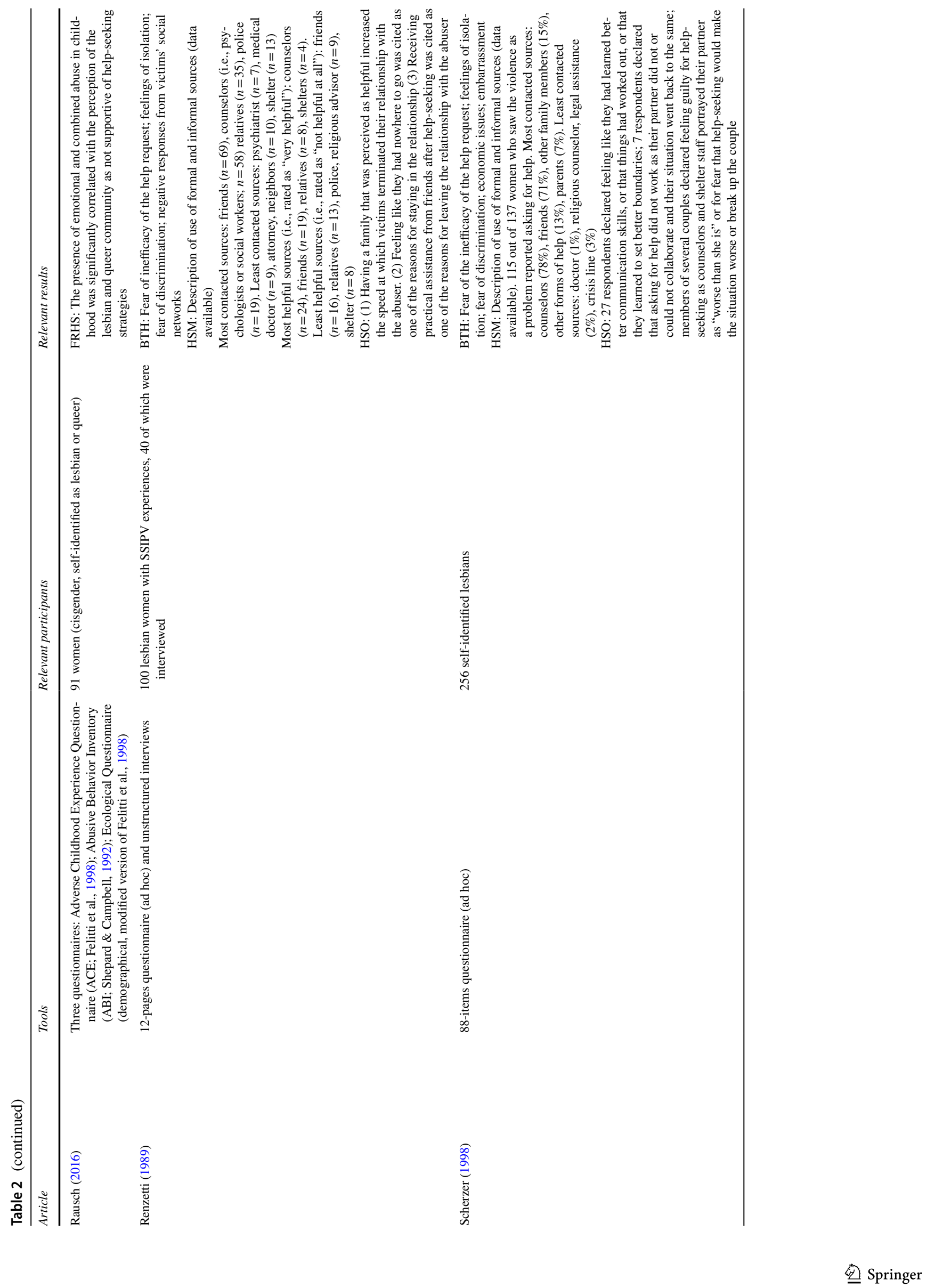




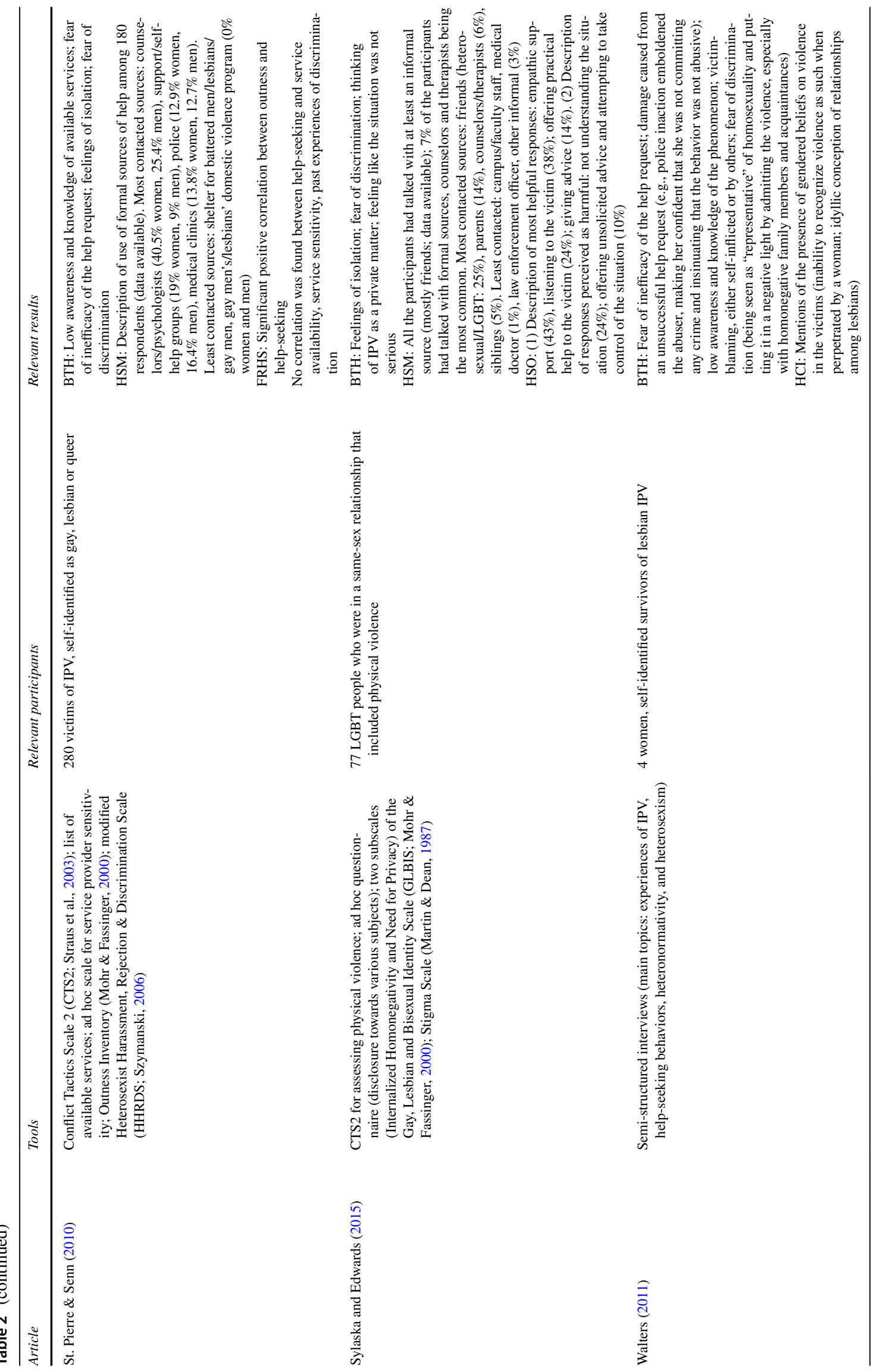


interaction effects between multiple layers of marginalization (e.g., due to a combination of ethnicity, gender, socioeconomic status, and sexual orientation).

Among the identified barriers, many themes are recurring. Three studies described feelings of isolation connected to the victims' status of sexual minority, which sometimes led them to avoid discussing the problem altogether, preventing them from seeking help. Bloom et al. (2015) reported as possible causes discrimination from friends and family, lack of relationship experience, or coming out status (i.e., the willingness or readiness to openly identify oneself as gay man or lesbian woman). A participant (a college staff member) highlighted this dynamic in the description of a survivor who felt the only one who accepted her sexuality was her physically abusing partner, which made it harder for her to talk about the abuse. Donovan and Barnes (2020) further highlighted how the minority status can lower relationship expectations (e.g., through fear of not finding another partner) and increase tolerance of abusive behaviors when combined with stigma and internalized stereotypes that assume dysfunctionality in LGBT relationships, resulting in a normalization of violence. Meza-de-Luna et al. (2015) also mention isolation as a key factor in IPV concealment: the lack of a strong and reachable support network produces a state of vulnerability which is compounded when the relationship exists in secrecy as in some same-sex relationships.

Hardesty et al. (2011) reported that the lesbian participants who attempted covert help-seeking (i.e., without revealing the violence) felt a stigma in the combination of being in a same-sex relationship and a victim of IPV: these participants were often embedded in social networks characterized by silence and secrets about the violence, its members sometimes complicit in hiding it, the experience of isolation worsened by a "don't ask, don't tell" climate. The experience of the participants who had tried to solve the problem alone was even harder: closeted mothers in abusive same-sex relationships, sometimes socially isolated and insecure about their sexuality, feared the possibility of negative reactions from their social circle if they were to reveal their sexual orientation or their involvement in IPV; additional fears included losing their jobs, being excluded by communities and being mistreated from service providers (e.g., healthcare professionals, police) (Hardesty et al., 2011).

Six studies found fear of discrimination to be a common report as well. Donovan and Barnes (2020) and Walters et al. (2011) observed how some participants feared being perceived by their social networks as the most representative member of their sexual orientation and, more generally, the LGBTQ community: the participants worried that revealing their involvement in violent couple dynamics would cast a negative light on the LGBT + community and on samegender relationships (e.g., someone using this violence as "proof" of their inherent unhealthiness).
Some authors (Renzetti, 1989; Irwin, 2006; St. Pierre \& Senn, 2010; Sylaska \& Edwards, 2015) found that many victims were afraid of talking about the violence to family, friends, and service providers as it implied revealing their sexual orientation, therefore stressing the importance of a strong, supportive social network.

Low awareness and knowledge about SSIPV played an important role in preventing victims and perpetrators alike from recognizing their experience of violence as a problem. Participants in several studies (Bloom et al., 2015; Freeland et al., 2018; Merrill \& Wolfe, 2000; Walters, 2011) are described as not being aware of the existence of SSIPV as a phenomenon, in part due to stereotypes that lead to not taking same-sex violence seriously and failure to categorize the violence as such. Donovan and Barnes (2020) and Donovan and Hester (2011) define as important factors a lack of representation and role models combined with the difficulty of accessing information about LGBT identities: these gaps are potentially filled by the abuser, who may try to deny the issue, attempt to normalize it as an expected part of same-sex relationships or engage in manipulation tactics (e.g., blaming the victim). Donovan and Hester (2011) also observed how some participants recognized the presence of violence in same-sex couples but did not believe it to be a problem, as they believed same-sex relationships to be more emotionally charged, and thus normalized the presence of violence, a finding mirrored in the study by Freeland et al. (2018).

Further normalization attempts were described by Oliffe et al. (2014): in some couples, both perpetrators and victims in a male same-sex relationship described physical violence as routine, due to the stereotype that men often use force with each other especially when enraged and did not define these behaviors as violence. Some of the interviewed participants (gay and bisexual men) saw partner violence as normal in the context of same-sex relationships between men, as they believed violence to be a normal, unproblematic behavior inherent to masculinity. Rigid ideals of masculinity sometimes led these participants to feelings of shame and self-blaming when victimized by violent partners (citing reasons such as not being strong enough or not being able to defend themselves): adopting a stoic ideal of masculinity (such as believing you have to "man up" when faced with problems) meant refusing to acknowledge violence as a problem, let alone a problem that could use an external person's help. In this study as well, the authors argue that the lack of representation of SSIPV in media and resources often meant that victims (especially those lacking relationship experience) had no model or frame of reference for acceptable and unacceptable behavior.

Furthermore, Meza-de-Luna et al. (2015) pointed out how violence committed by women (both lesbian and 
heterosexual) tends to be detected and recognized less. In cases where participants were aware of SSIPV as a problem, many of them were nonetheless unaware of available resources that took their sexual orientation into account (Freeland et al., 2018).

The problems connected to low awareness and knowledge have been mentioned in the context of services as well. Some participants of Freeland et al. (2018) study mention how attempts to reach out to IPV organizations did not help, as service providers were perceived as not knowledgeable about SSIPV, often made assumptions about their needs, and sometimes diverted their request to other organizations; similar problems were found with the police as well, whom the participants could additionally distrust due to previous experiences of homonegativity. St. Pierre and Senn (2010) reported how the participants of their study rated same-sex specific services as "more sensitive" than mainstream, nonspecific services: mainstream services were rated as only "somewhat sensitive." The thematic analysis conducted by the authors defined sensitive services as possessing certain features: they should be knowledgeable and resourceful; aware of SSIPV-specific programs and able to make referrals; have access to SSIPV literature; they should know the differences and similarities between SSIPV and HIPV and have knowledge or experience of LGBT-specific issues; finally, they should be nonjudgmental, and should not be heterosexist or homophobic.

The across-the-board influence of a heteronormative conception of IPV, which can be identified among victims, perpetrators and service providers alike is often pointed out as a potential cause of a wide variety of the barriers described. Imagining and defining IPV as primarily the stereotypical situation of a heterosexual man inflicting physical violence on a female partner is one of the main sociocultural influences on the definition and recognition of IPV as a problem: stereotypes, myths and beliefs related to gender and sexual orientation can change the perception of what counts as acceptable behavior and what counts as violence in victims, perpetrators, and service providers.

Donovan and Barnes (2020) describe how cisgendered heteronormativity (i.e., the assumption that a gender identity corresponding to the culturally determined gender roles for one's birth sex, coupled with a heterosexual sexual orientation, is the standard) results in a lack of models, representations, and information about LGB/T relationships, adding to the feelings of isolation. In turn, this may influence all stages of help-seeking behavior (Liang et al., 2005): recognizing that there is a problem, deciding whether to do something about it and selecting a source of help. The authors argue that the success of feminist scholars in framing domestic violence as "a problem of heterosexual men for heterosexual women, a problem of physical violence and a problem of a particular presentation of gender: the 'big' strong man being physically violent to the small 'weak' woman" (Donovan \& Barnes, 2020, p.8) had several side effects: it concealed the possibility that women could be perpetrators and men could be victims; it twisted the perception of risk in SSIPV through myths and stereotypes, as men may be perceived as naturally able to defend themselves as well as more resistant to harm (downplaying violence between gay men), while women may be perceived as harmless and less risky than men (downplaying violence between lesbians). Finally, using a binaristic storytelling of "strong" and "weak" plays into gender-essentialist views (i.e., "observed differences between men and women are attributed to a fixed essence, which is thought to be universal and is often defined in terms of individuals' biological capacities"; Ching et al., 2020, p. 427 ) and paints the picture of a defenseless and blameless victim, an aspect which may be more nuanced in reality (Donovan \& Barnes, 2020).

Donovan and Hester (2011) described how the construction of domestic violence as a heteronormative, primarily physical phenomenon fueled the low awareness and lack of recognition they observed in their study: some participants did not recognize their personal experience as IPV because they did not have any role model or representation for comparison, an issue compounded by the fact that many of them were in their first same-sex relationship and therefore started to assume the violence was part of the experience, an aspect that is found in the study conducted by McDonald (2012) and Merrill and Wolfe (2000) as well.

A similar dynamic can be observed in violent relationships between lesbians: the study conducted by Irwin (2006) found some participants used a gendered frame of reference when considering definitions of violence, believing women (stereotypically associated with caring, mild behaviors, as well as victimhood rather than perpetration) to be incapable of violence. Violent behaviors perpetrated by women are retroactively justified in some way, minimized, or placed outside of the definition of violence altogether, an issue that is also found in HIPV. Some participants idealized intimate relationships between women and held the lesbian community to an idyllic standard, believing them to be peaceful and free from conflict, only applying a definition of IPV when it fit the heteronormative frame of reference, a finding mirrored in the study by Walters (2011). As an example, in the study conducted by Hardesty et al. (2011), a woman attempting covert help-seeking reported feeling shame and embarrassment in the admission of violence in a female-female relationship: this participant was shocked at the possibility that women could be violent as well, expecting the relationship between two women to be more emotional, nurturing, and caring.

In the context of services and service providers, a gendered frame of reference can often be observed, leading 
some of them to not recognize violent behavior as a problem. Freeland et al. (2018) observed that police officers may not recognize violence between same-sex couples due to adopting a heteronormative frame of reference for IPV, and may minimize a victim's experience of violence, or even deny help altogether after a request for support, citing stereotypes and myths as reasons (e.g., not believing that a gay man or a woman could hurt someone). To an extent, this was also observed in some counseling services and IPV organizations.

\section{Help-Seeking Modes}

When experiencing IPV, choosing to seek help implies the key decision of selecting a source of help. These sources tend to be divided into formal (i.e., professionals and services that are at least somewhat specialized in some form of support) and informal (i.e., people who may have no specialized training but have some kind of relationship with the victim); other sources may be defined as semi-formal (i.e., may have no specialized training but could be defined as an organization an individual may turn to for help). Formal sources include subjects such as IPV shelters or organizations, therapists or mental health professionals, counselors, physicians or medical professionals, the police. Informal sources include subjects such as immediate family, relatives, friends, extended communities, or acquaintances; semi-formal sources include subjects such as churches. The included studies detailed how the involved people choose a certain source of help and what their preferences were, often highlighting some of the issues inherent in the several types of sources. The number and kind of contacted sources as well as their perceived helpfulness varied between the studies. However, several findings were shared among some of them, keeping in mind that the circumstances, definitions, and descriptions of the various studies were very specific, and attempting to summarize them leads to a certain loss of detail. Furthermore, the various studies' publication dates are noteworthy and to be kept in mind while reading their results, as the last 30 years have seen a generalized increase in the public sensitivity and knowledge about LGBT issues, a phenomenon mirrored in the gradual increase of perceived helpfulness of formal sources of help.

Eight of the studies (Renzetti, 1989; Scherzer, 1998; Merrill \& Wolfe, 2000; McClennen et al., 2002; St. Pierre \& Senn, 2010; Sylaska \& Edwards, 2015; Ngo, 2018; Di Battista et al., 2020) provided quantitative data about the sources of help their participants contacted (e.g., percentages or number of respondents; see Table 2 for a summary of the most contacted sources). Moreover, six different studies (Irwin, 2006; Donovan \& Hester, 2011; Hardesty et al., 2011; Guadalupe-Diaz, 2013; Oliffe et al., 2014; Freeland et al., 2018) did not provide detailed breakdowns, but nevertheless provided a description of the participants' experiences when selecting a source of help.

Among these studies, a clear use of informal sources can be identified.

All the seven studies surveying informal sources and providing quantitative data found friends and family (i.e., parents, relatives, or siblings) to be in the top three sources participants turned to when they sought help. Friends, in particular, were listed as the most common contacted source in six (Renzetti, 1989; Merrill \& Wolfe, 2000; McClennen et al., 2002; Sylaska \& Edwards, 2015; Ngo, 2018; Di Battista et al., 2020) out of seven of these, ranging from 25\% (Sylaska \& Edwards, 2015) to $85 \%$ (Merrill \& Wolfe, 2000). The studies providing qualitative descriptions (Irwin, 2006; Donovan \& Hester, 2011; Hardesty et al., 2011; Guadalupe-Diaz, 2013; Oliffe et al., 2014; Freeland et al., 2018) corroborated this aspect as well: among participants who sought help, turning to informal sources was often the most common choice.

The use of several different formal sources was documented as well. While the frequency of contact significantly varied between studies depending on the specific source, some of them stood out.

Counselors appeared to be the most contacted formal source. This category was sometimes defined verbatim, while other times explicitly included several different professionals (e.g., psychologists, psychiatrists, social workers, therapists). In the studies that provided quantitative data, frequency of contact varied between 6\% (Sylaska \& Edwards, 2015) and 78\% (Scherzer, 1998), but all of them (Renzetti, 1989; Scherzer, 1998; Merrill \& Wolfe, 2000; McClennen et al., 2002; St. Pierre \& Senn, 2010; Sylaska \& Edwards, 2015; Ngo, 2018; Di Battista et al., 2020) found this category to be among the top three contacted sources. In this case as well, the studies providing qualitative descriptions mostly corroborated this finding (see Table 2). Two studies (Merrill \& Wolfe, 2000; Di Battista et al., 2020) found gay and lesbian agencies to be contacted somewhat often as well. Other formal sources were contacted sparingly, some of them standing out among the least contacted sources. The police, organizations dealing primarily with HIPV (e.g., domestic violence agencies, IPV shelters), and crisis hotlines were often found to be contacted by less than $20 \%$ of the participants (Renzetti, 1989; Scherzer, 1998; Merrill \& Wolfe, 2000; Di Battista et al., 2020); this was also found to be the case in two of the studies providing qualitative descriptions (Donovan \& Hester, 2011; Freeland et al., 2018).

Six studies (Freeland et al., 2018; Irwin, 2006; McClennen et al., 2002; Merrill \& Wolfe, 2000; Renzetti, 1989; Scherzer, 1998) surveyed the perceived level of helpfulness of the contacted sources.

Informal sources (mostly friends and family) were often found to be ambivalently helpful (Irwin, 2006; McClennen 
et al., 2002; Merrill \& Wolfe, 2000; Renzetti, 1989), that is, the experiences of participants seemed to vary, some finding them helpful and others not helpful at all. Two studies (Freeland et al., 2018; Irwin, 2006) nevertheless underscored the importance of the presence of supportive informal networks, especially in cases where other sources of help may be unavailable or provide negative experiences of help-seeking, such as in the presence of an unsupportive family or formal services that are homonegative or unable to support gay and lesbian people properly. In one study (Irwin, 2006), however, participants warned of a tendency to hide the problem in lesbian communities, a tendency that is mentioned by other authors as well (Meza-de-Luna et al., 2015; Walters, 2011).

Formal sources were mostly found to be unhelpful (Freeland et al., 2018; McClennen et al., 2002; Renzetti, 1989; Scherzer, 1998). Previous negative experiences with formal sources of help were one of the reasons behind respondents turning to informal ones (Freeland et al., 2018; Irwin, 2006). In particular, participants in two studies (Freeland et al., 2018; Di Battista et al., 2020) identify IPV organizations as not very helpful, as they were not perceived as knowledgeable about the specificities of SSIPV and were believed to be catering mainly to heterosexual women. The police and the criminal justice system were regarded with distrust as well, despite the desire for institutional involvement. Two studies (Donovan \& Hester, 2011; Ngo, 2018) further highlighted relevant differences between the preferred help-seeking sources in SSIPV and HIPV: in the study conducted by Donovan and Hester (2011), the police is ranked as second preference in HIPV and very last preference in SSIPV. The authors find a gendered distinction in this source selection: in HIPV, women were significantly more likely than men to contact the police ( $24 \%$ vs $7 \%$ ), while this distinction was less pronounced in SSIPV (11\% vs 7\%). Ngo (2018) found gendered differences in help-seeking behavior for stalking as well: male-male dyads were the least likely to look for both formal and informal help.

The tendency to avoid seeking help from the police may be explained by some of the discussed barriers. These studies' respondents often worried about not being taken seriously, or that their request for help would be met with homophobia (Donovan \& Hester, 2011; Freeland et al., 2018; Irwin, 2006; Meza-de-Luna et al., 2015; Oliffe et al., 2014; Renzetti, 1989; Walters, 2011). Some respondents suggested that reporting the violence to the police could make things worse with their partner: the perpetrator could escalate the violence after finding out about the reporting, feeling either emboldened by the lack of institutional intervention or vengeful at the perceived affront (Donovan \& Hester, 2011). Other participants mentioned that their request was ineffective, in part due to the failure of the heteronormative, gendered frame of reference often employed by the officers when deciding how to proceed: this sometimes led to a double arrest, the arrest of the most masculine-presenting member of the dyad or no action at all (Donovan \& Hester, 2011; Merrill $\&$ Wolfe, 2000).

Despite these perceptions of unhelpfulness, there are some notable exceptions among formal sources. Counselors were described as helpful in some studies (Freeland et al., 2018; Irwin, 2006; Merrill \& Wolfe, 2000; Renzetti, 1989). Organizations that were tailored to gay and lesbian people were described as very helpful as well, such as gay men's domestic violence programs or general agencies, or counseling centers with mental health professionals (Freeland et al., 2018; Irwin, 2006; Merrill \& Wolfe, 2000). Overall, the common denominator between these services and professionals seemed to be knowledge and sensitivity towards LGB themes and issues. However, St. Pierre and Senn (2010) found SSIPV-specific services to be scarcely available (note: the study was conducted in Canada).

Oliffe et al. (2014) reported how the help-seeking may happen after the relationship is over, as an attempt to recover from the damages sustained during the abusive relationship: some participants mention contacting friends and healthcare professionals in order to cope with the ensuing depression. Many victims decided to avoid help-seeking and attempted a number of other possibilities (Freeland et al., 2018): sorting things out with their partner, moving to another house, changing their daily habits, taking proactive defensive countermeasures, engaging in solitary activities such as meditation or artistic endeavors. Sometimes, respondents turned to unhealthy coping mechanisms such as substance abuse or even decided to ignore the problem.

Finally, several studies found a large part of the victims chose to avoid help-seeking. Guadalupe-Diaz (2013) collected worrying data in this regard: among those who had experienced IPV or a serious form of partner abuse, " $57,1 \%$ did not seek any form of help, $65,9 \%$ did not seek any formal help, and $65,5 \%$ did not turn to friends and family" (p. 25). This rate of disclosure is mirrored by the participants in Sylaska and Edwards (2015): 64.9\% did not disclose their experience to anyone, citing reasons such as not believing the violence was a big deal or classifying it as not serious (83\%), believing the violence was a private matter $(21 \%)$, worrying about others' reactions $(21 \%)$ or even feeling like they had no one to tell (7\%). Di Battista and colleagues find similar results as well: $55 \%$ of the respondents talked to no one about their experience of emotional abuse; this was particularly dire in victims of denigration, and in victims of very frequent abuse (22\% talked to no one). 


\section{Factors Related to Help-Seeking}

Among the included studies, some authors attempted to determine the role of several factors in determining whether help-seeking behaviors would occur.

Feelings about one's own sexual orientation are identified as an influence by several studies. Three (St. Pierre \& Senn, 2010; Hardesty et al., 2011; Guadalupe-Diaz, 2013) described a lower chance of help-seeking among participants that were "closeted," who showed higher levels of internalized homonegativity, minority stress, feelings of shame. These participants sometimes anticipated (or received) stigmatizing responses when looking for help and therefore tried to solve the problem alone. On the contrary, three studies (St. Pierre \& Senn, 2010; Hardesty et al., 2011; McDonald, 2012) highlighted a higher likelihood of help-seeking in participants who showed positive feelings about one's own sexual orientation, and who were fully and openly out (i.e., had performed a "coming out," had in some way disclosed their sexual orientation to their social circles). The presence of positive social experiences about one's own sexual orientation (and the lack of negative ones) seemed to result in a higher chance of help-seeking, such as in the presence of a network of services, relationships, and communities supportive of the victims' sexual orientation.

Guadalupe-Diaz (2013) found three significant relationships when estimating the chance of help-seeking among victims: a lower economic class was found moderately correlated with a lower chance of requesting formal help; a strong relationship was found when comparing men and women of the same economic class, with men being significantly less likely to ask for help than women; finally, when comparing men between lower and higher economic classes, the ones having a lower economic class were significantly less likely to ask for help. The presence of a favorable socio-economic status (e.g., having a job) was found to be positively associated with help-seeking by Hardesty and colleagues (2011) as well.

In the study by Coston (2019), the author identifies several key findings. The study includes behaviorally bisexual women, that is, women who regardless of self-identification as bisexual had intimate relationships with both genders (also defined as "non-monosexual"). Behaviorally nonmonosexual women were significantly more likely than behaviorally heterosexual women to report IPV care needs, while no difference was found between heterosexually identified and bisexually identified women; non-monosexual women also reported the same health care needs regardless of the gender of the abuser. The single most significant factor that decided whether the victims would seek help was the severity of the received injuries: no other factor was found to be significantly impactful on the reporting of IPV needs, including age or self-identification as bisexual. When not taking injury severity into account as a control, the only other factor that was found significant was inequality, as non-monosexual women with less social power tended to be in higher need of post-victimization health care.

The severity of the injury was prominently discussed as a major motivation for help-seeking by the participants of Hardesty and colleagues (2011) as well, together with the perception of the violence as intolerable: the victims cited reasons such as an escalation of violence impacting negatively on their health, a sense of physical and emotional fatigue, or an impact on their children's or their new partner's health. Surveying the help-seeking process in stalking victims, Ngo (2018) found that feeling intimidated by the stalker seemed to heighten the likelihood of help-seeking (police and informal networks). Three more factors (age, marital status, perpetrator ethnicity) were found significant in determining requests for help in F-F couples, but they were found not to be significant in M-M couples.

Rausch (2016) found that the presence of childhood emotional abuse and combined childhood abuse both significantly correlated with the perception that the lesbian and queer community was not accepting of help-seeking strategies.

Finally, Di Battista et al. (2020) found that participants who experienced "very frequent abuse" had a statistically significant lower likelihood of talking about it with anyone (22\% of participants in this category disclosed their situation). Victims of denigration, in particular, were the least likely to talk about the abuse.

\section{Help-Seeking Outcomes}

Four studies described the outcomes of the help-seeking process.

In contrast with other included studies, almost all the participants (90\%) surveyed by Coston (2019) who reported needing care declared receiving the help they sought.

Renzetti (1989) detailed how helpful, positive responses from help providers played a major role in the decision of leaving or continuing the abusive relationship. Having a supportive family that was perceived as helpful significantly reduced the time the victims took to leave their abusive partner; similarly, having practical assistance (e.g., moving out of the house, getting temporary shelter) from friends was a positive contribution to the decision to leave. On the contrary, negative responses from sources inhibited the victims from leaving their relationship, reinforcing their low selfesteem and increasing their sense of isolation.

In the study conducted by Scherzer (1998), 27 respondents mentioned several positive outcomes after asking for help: learning better communication skills, learning to set better boundaries, or declared that things worked out in some way. A mention of perpetrators turning to help sources 
is found as well, respondents who disclosed acting abusively and attempted to learn better coping tools, better boundarysetting and better communication. However, some respondents mentioned negative outcomes: feeling guilty for the negative portrayal of the abusive partner, fearing therapists would turn them against their partner or even split up the couple, some even experiencing homophobia from service providers.

Finally, the participants in the study conducted by Sylaska and Edwards (2015) gave a detailed explanation of what responses they perceived to be most helpful when they turned to help sources. Empathetic support (43\% of the participants), active listening (38\%), receiving practical support $(24 \%)$ or getting advice $(14 \%)$ were all responses perceived as helpful. On the contrary, the most harmful responses they had encountered involved sources saying they did not understand their situation (24\%) or attempting to give unsolicited advice and trying to take control of the situation (10\%).

\section{Discussion}

The objective of this systematic review is to summarize the state of the art of scientific evidence on the help-seeking process in SSIPV. To the authors' knowledge, this is the first systematic review on this specific topic.

The themes emerging from the included scientific literature paint a worrying picture. SSIPV appears to be a common and severely damaging experience (Rollè et al., 2018, 2021).

Considering how common the problem is estimated to be and how serious the consequences of abuse can become, the number of participants who experienced IPV or serious forms of abuse without seeking any help (57.1\%; GuadalupeDiaz, 2013; 64.9\%; Sylaska \& Edwards, 2015) should be cause for concern. The numerous barriers to help-seeking explain several of the factors in play when it comes to the decision to seek help, and why so many people end up not doing so. A widespread lack of awareness and knowledge about SSIPV and LGB themes, combined with feelings of isolation, results in a perception of unhelpfulness in many formal sources of help.

The frequent adoption of a heteronormative conception of IPV further aggravates the invisibility of the problem and the disconnection between help-seekers and sources. Due to the widespread presence of gendered beliefs about violence (Hine et al., 2020b) in the public, in service providers (Freeland et al., 2018), in victims and in perpetrators, situations that do not fit the stereotypical conceptualization of IPV (i.e., a heterosexual man perpetrating physical violence on a heterosexual woman) have a lower chance of the violence being recognized as a problem: this is not an issue in SSIPV alone, but involves male victims (Hine et al., 2020a) and female perpetrators
(Freeland et al., 2018; Irwin, 2006) of violence as well, who may not recognize the situation they are in.

Perhaps most striking is the fact that many of the discussed issues have remained unsolved despite being identified more than 30 years ago. As an example, some of the identified barriers (fear of discrimination, fear of the inefficacy of the help request) have been described both in the earliest included studies (Renzetti, 1989; Scherzer, 1998) and some of the most recent ones (Freeland et al., 2018; Donovan $\&$ Barnes, 2020). Furthermore, some formal sources of help (e.g., police, shelters) have kept their perception of unhelpfulness, several of the negative dynamics of the help request (heteronormative conception of IPV, low cultural competence) remaining intact throughout the decades. This finding emphasizes the complexity of the problem, the need for more research and the development of interventions. Overall, the findings of this systematic review appear to outline several problems which entail implications on different levels such as clinical practice, policies, and interventions.

Almost universally, help-seekers seem to prefer turning to informal sources first (Donovan \& Hester, 2011; Irwin, 2006; Merrill \& Wolfe, 2000; Renzetti, 1989; Sylaska \& Edwards, 2015). Some hypotheses for this behavior include a lack of familiarity with available services (Bloom et al., 2015; Freeland et al., 2018; Merrill \& Wolfe, 2000; Walters, 2011), previous negative experiences with formal sources (Freeland et al., 2018; Irwin, 2006) or a preference for the existing support network of friends, family, and extended community (McDonald, 2012). While supporting informal networks may be useful, feelings of isolation often prevent victims from accessing them, or they may not have access to a supporting informal network at all (Bloom et al., 2015; Meza-de-Luna et al., 2015). Furthermore, informal sources of help tend not to have specialized knowledge of how to properly handle an SSIPV situation and may suggest counterproductive or ineffective strategies while also being vulnerable to biases, stereotypes, and myths. Therefore, an important part of mitigating harm from SSIPV may involve improving the availability of formal SSIPV-specific resources and services (St. Pierre \& Senn, 2010), as well as supplying existing sources with the right tools (Bloom et al., 2015; Furman et al., 2017).

The identification of homonegative attitudes as a barrier (St. Pierre \& Senn, 2010; Hardesty et al., 2011; GuadalupeDiaz, 2013) highlights the need for interventions aimed at their reduction. These are far from a relic of the past and appear to be still heavily present on an international level (ILGA-Europe, 2021). A reduction in homonegative language among involved subjects, as well as attempts to reduce homonegativity in the public opinion would possibly help reduce this particular barrier. The structural discrimination gay and lesbian people encounter, linked to homonegative and heterosexist attitudes, influences the chances 
of perpetration and victimization (Hardesty et al., 2011; McDonald, 2012) and hinders the help-seeking process. Additionally, addressing these forms of discrimination may reduce some of the negative effects of the intersection of multiple conditions (e.g., stemming from socio-economic factors, and one's minority status).

A key factor that appears to influence the perceived usefulness of formal services is their cultural competency about LGB themes and the specificities of SSIPV. Several of the studies (Renzetti, 1989; Scherzer, 1998; Donovan \& Hester, 2011; Hardesty et al., 2011; Freeland et al., 2018; Di Battista et al., 2020) include accounts of formal sources' unhelpfulness and point out how they are among the least used sources, but some testimonies make exceptions for services who were perceived as sensitive and knowledgeable about LGB themes. The studies characterizing minority stress and internalized homonegativity as a barrier to services (Bloom et al., 2015; Sylaska \& Edwards, 2015) seem to further confirm the importance of cultural competency. In an apparent reversal of these findings, the recent study conducted by Coston (2019) finds almost all (90\%) of its respondents declaring having received the help they needed. The author, however, hypothesizes this finding might be due to an increase over time in cultural competency about LGB themes in healthcare workers, a trend that, if verified, would give further credence to this hypothesis. Furthermore, the author advises caution, highlighting the limitations of this finding: the study investigated neither the level of detail help-seekers gave about their victimization (including whether they mentioned their sexual orientation) nor the quality of the care received post-victimization (quality care or simple physical injury treatment). An application of these findings might involve developing training programs for increasing the cultural competency of service providers about LGB themes, in order to reduce barriers to services and support the recognition of the problem. This need for cultural competency applies to research as well, as studies dealing with IPV would benefit from taking sexual orientation and its specificities into account.

Finally, addressing the heteronormative conception of IPV would be extremely important: the use of gender-neutral terminology when dealing with IPV and better representation of more diversified situations of the phenomenon would be a helpful start on its reduction. This would not only help reduce barriers to services for people whose sexual orientation does not fit into the heteronormative narrative, but also provide a better help-seeking experience for victims and perpetrators that do not fit the stereotype, such as male victims and women perpetrators.

The application of essentialist reasoning to gender and sexual orientation by the involved parties (victims, perpetrators, and sources of help alike) may be shaping experiences of help-seeking as well, sustaining the heteronormative conception of partner violence observed in the studies. The conceptualization of gender and sexual orientation as a binary ("male or female," "gay or straight"), rather than a wide and multifaceted spectrum that does not inherently possess a default, natural setting, often carries other associations with it. The stereotypical associations between "masculinity and aggression" and "femininity and victimhood," while sometimes treated as based in some form of nature, clearly do not withstand the complex reality of partner violence, as exposed by the studies' participants themselves. Adopting an intersectional perspective that takes multiple, intersecting identities into account might promote a conceptualization of violence that does not rely on gender binarism (Rinaldi, 2013; Serri et al., 2016). On a wider sociocultural level, promoting the de-essentialization of gender and sexual orientation might provide parties with a better understanding and awareness of partner violence as a phenomenon, abandoning a binaristic paradigm that is frequently misleading.

\section{Limitations}

The present research analyzed the recurring themes found throughout the included literature. However, it is not a metaanalysis, and as such, it may not be used to derive aggregate statistical insights about any of the explored topics.

Secondarily, the abstracts that were selected for fulltext review were limited to articles written in the English language. Because of this, several articles written in other languages could not be examined. It would be important to consider these international perspectives as well in order to identify possible sociocultural variations on the explored themes.

\section{Future Directions}

While research interest on the topic seems to be on a slight upwards trend when considering the number of decade-todecade studies, SSIPV studies are still extremely limited in quantity and depth, far from enough to reach a scientific consensus on several aspects.

While some theoretical models of help-seeking were discussed and used (Grigsby \& Hartman, 1997; Liang et al., 2005), few studies made use of them (Hardesty et al., 2011; Donovan \& Barnes, 2020), and both were conceived with women as victims of HIPV in mind. The development and adoption of updated theoretical models of help-seeking that attempt to go beyond gendered frames of reference might produce a useful framework for more coherent and comparable studies in the literature.

Several types of studies seem to be very few and conducting more of them may produce useful insight in these areas. For example, the generalizability of the included results may be examined more thoroughly if more quantitative or mixed 
methods studies were conducted. Studies focused on nonphysical forms of violence would allow us to have more information on more nuanced forms of IPV. Examining the experiences of formal service providers might prove valuable as well, as the existing studies (Donovan et al., 2011; Freeland et al., 2018) hint at a strong presence of heteronormative, gendered frames of reference and conceptions of IPV.

The small number of included studies was partly due to a high exclusion rate, as in many cases a few key details were missing which made publications ineligible: studies that defined "LGB/T/Q/+ people" as the target population often collapsed all of their results into one category. Without a breakdown of their results by sexual orientation, such as detailing whether a certain finding concerned lesbian women, bisexuals, or gay men specifically, it was sometimes impossible to discern possibly useful information such as differences between their experiences. The inclusion of bisexual people without specifying whether the relationship in which they experienced violence was with a person of the same or opposite gender proved to be a particularly common issue, and a frequent cause of exclusion. This issue implies a twofold loss of detail: not being able to determine the gender of the victim or abuser may blind researchers to the specificities of M-M/F-F dyads; furthermore, it effectively invisibilizes bisexual victims and perpetrators, preventing us from detecting whether bisexual people experience specificities that shape their experience of IPV and that are exclusive to their sexual orientation, an aspect that is suggested by their comparatively higher victimization rates and experiences of marginalization (Messinger, 2011; Walters et al., 2013).

Similarly, while clearly well-intentioned, the unspecified and superficial inclusion of trans people, people who identify as queer or anyone else that falls under the everevolving umbrella terms referring to this community might mean losing sight of their specificities while also possibly polluting the rest of the data pool with undetected interfering factors. Future studies may consider taking these issues into account when investigating SSIPV, specifying these important missing pieces of information and attempting to control for interferences when possible.

Data on several of the explored topics remains scarce and sometimes outdated.

For the most part, studies tend to focus almost exclusively on the victim's experiences. Data on perpetrators of violence seems exceedingly rare, only two (Scherzer, 1998; McDonald, 2012) studies making explicit mention of having included perpetrators among their participants. Given the frequent lack of recognition of violence (partly due to gendered frames of reference and a heteronormative conception of partner violence), an exploration of perpetrators' beliefs, attitudes and behaviors might offer insight on developing possible perpetrator programs that take sexual orientation into account.
Help-seeking outcomes were mentioned in only four of the studies (Coston, 2019; Renzetti, 1989; Scherzer, 1998; Sylaska \& Edwards, 2015): having more information on this part of the process might provide useful insights on how to best support victims and perpetrators, while also informing public policy on which services work best in this scenario. The most recent detailed data on the help-seekers' attitudes (e.g., perceptions of source helpfulness, how they choose a certain source) comes from Irwin (2006), and newer studies on the same topic might provide information on the sensitivity of various services, an aspect that might have changed significantly in the elapsed time span. Additionally, conducting a study applying a comparative approach to different sources of help may be useful to uncover differences in the help-seeking process, such as whether the effects of the help request are different among different sources.

A noticeable disparity can also be found when comparing the amount of literature produced in English-speaking countries with the number of articles published in non-Englishspeaking countries: producing more studies in diverse cultural contexts might offer insight into whether cultural differences play a role in this field. Furthermore, future studies comparing diverse cultural contexts might provide useful perspectives on the specificities of SSIPV in different cultures.

Finally, more resources are needed to better standards of care for formal and informal sources. Some of the authors of the included studies have proposed several suggestions. Beyond the discussed suggestions, to the authors' current knowledge, the included literature did not mention the existence of shared best practices, guidelines or training programs for healthcare providers that are widely promoted and applied. As suggested by some authors, (McClennen et al., 2002; Merrill \& Wolfe, 2000; Meza-de-Luna et al., 2015; Sylaska \& Edwards, 2015) the development of these elements might improve the quality of formal care for gay and lesbian people involved in SSIPV, granting them access to culturally competent services which may reduce their fears of discrimination. The establishment of new services tailored to SSIPV that are able to address the specific needs of this population (such as psychological support services, shelters, or helplines) may be a fruitful endeavor in attempting to make quality care more accessible, as the preliminary evidence of the availability of such services (Freeland et al., 2018; Donovan \& Barnes, 2020) suggests they are rare and often geographically limited. Furthermore, creating and promoting dissemination programs for victims, perpetrators, service providers, and informal sources that aim to debunk the numerous myths and stereotypes about the topic (Merrill \& Wolfe, 2000; Rausch, 2016; Donovan \& Barnes, 2020) may improve awareness of the phenomenon and of the available help-seeking strategies. 


\section{Conclusions}

The SSIPV phenomenon poses major challenges to victims, couples, families, healthcare providers, peers, researchers, and associations. Heteronormative conceptions of IPV, gender role stereotypes, and myths about the topic have severely limited the recognition of violent behavior, the activation of relevant support systems, and, sometimes, their helpfulness (Cannon \& Buttell, 2015; Russell, 2015). Services tailored to SSIPV are still scarce (Calton et al., 2015), and barriers to these services appear widespread, limiting their accessibility and effectiveness.

The development of policies, programs, and interventions that aim to counter the negative effects of SSIPV is urgently needed, as are research initiatives that aim to cover the wide gaps in knowledge.

Author Contribution Creation of the frame used in this review and the selection of the papers: FS, TT, and LR. Review of the literature: FS, and TT. Searching of the articles discussed in the review, data extraction, and interpretation of the results: FS, TT, and LR. Supervision of the entire work: LR. All authors were involved in the discussion, writing, and revision of the manuscript and they gave the final approval of the version to be published.

Funding Open access funding provided by Università degli Studi di Torino within the CRUI-CARE Agreement.

\section{Declarations}

Conflict of Interest The authors declare no competing interests.

Open Access This article is licensed under a Creative Commons Attribution 4.0 International License, which permits use, sharing, adaptation, distribution and reproduction in any medium or format, as long as you give appropriate credit to the original author(s) and the source, provide a link to the Creative Commons licence, and indicate if changes were made. The images or other third party material in this article are included in the article's Creative Commons licence, unless indicated otherwise in a credit line to the material. If material is not included in the article's Creative Commons licence and your intended use is not permitted by statutory regulation or exceeds the permitted use, you will need to obtain permission directly from the copyright holder. To view a copy of this licence, visit http://creativecommons.org/licenses/by/4.0/.

\section{References}

American Psychological Association. (2020). Heteronormativity. In APA Dictionary of Psychology. Retrieved February 2nd, 2021, from https://dictionary.apa.org/heteronormativity

American Psychological Association. (2012). Intimate partner violence-Facts \& resources. Retrieved May $1^{\text {st }}, 2021$, from https:// www.apa.org/topics/violence/partner

Barrett, B. J. (2015). Domestic violence in the LGBT community. Available at: http://socialwork.oxfordre.com/view/ https://doi.org/10. 1093/acrefore/9780199975839.001.0001/acrefore-9780199975839e-1133
Bonechi, A., \& Tani, F. (2011). Italian adaptation of the multidimensional measure of emotional abuse (MMEA): TPM-testing, psychometrics. Methodology in Applied Psychology, 18(2), 65-86.

Bloom, T., Gielen, A., \& Glass, N. (2015). Developing an app for college women in abusive same-sex relationships and their friends. Journal of Homosexuality, 63(6), 855-874. https://doi.org/10. 1080/00918369.2015.1112597

Calton, J. M., Cattaneo, L. B., \& Gebhard, K. T. (2015). Barriers to help seeking for lesbian, gay, bisexual, transgender, and queer survivors of intimate partner violence. Trauma, Violence, \& Abuse, 17(5), 585-600. https://doi.org/10.1177/1524838015585318

Cannon, C., \& Buttell, F. (2015). Illusion of inclusion: The failure of the gender paradigm to account for intimate partner violence in LGBT relationships. Partner Abuse, 6(1), 65-77. https://doi.org/ 10.1891/1946-6560.6.1.65

Cannon, C. E. (2019). What services exist for LGBTQ perpetrators of intimate partner violence in batterer intervention programs across North America? A Qualitative Study. Partner Abuse, 10(2), 222 242. https://doi.org/10.1891/1946-6560.10.2.222

Ching, B. H. -H., Xu, J. T., Chen, T. T., \& Kong, K. H. C. (2020). Gender essentialism, authoritarianism, social dominance orientation, and filial piety as predictors for transprejudice in Chinese people. Sex Roles, 83(7-8), 426-441. https://doi.org/10.1007/ s11199-020-01123-3

Coston, B. M. (2019). Patterns of post-traumatic health care service need and access among bisexual and non-monosexual women in the U.S. Journal of Aggression, Maltreatment \& Trauma, 29(3), 348-364. https://doi.org/10.1080/10926771.2019.1572401

Craft, S. M., Serovich, J. M., McKenry, P. C., \& Lim, J. (2008). Stress, attachment style, and partner violence among same-sex couples. Journal of GLBT Family Studies, 4, 57-73. https://doi.org/10. 1080/15504280802084456

Di Battista, S., Paolini, D., Pivetti, M., Biondi, P., Balsamo, M., Carlucci, L., ... Mazzoni, S. (2020). Emotional abuse among Lesbian Italian women: Relationship consequences, help-seeking and disclosure behaviors. Journal of Gay \& Lesbian Mental Health, 25(2), 175207. https://doi.org/10.1080/19359705.2020.1843582

Donovan, C., \& Hester, M. (2011). Seeking help from the enemy: Helpseeking strategies of those in same-sex relationships who have experienced domestic abuse. Child \& Family Law Quarterly, 23, 26-40.

Donovan, C., \& Barnes, R. (2020). Help-seeking among lesbian, gay, bisexual and/or transgender victims/survivors of domestic violence and abuse: The impacts of cisgendered heteronormativity and invisibility. Journal of Sociology, 56(4), 554-570. https://doi. org/10.1177/1440783319882088

Duke, A., \& Davidson, M. M. (2009). Same-sex intimate partner violence: Lesbian, gay, and bisexual affirmative outreach and advocacy. Journal of Aggression, Maltreatment \& Trauma, 18(8), 795-816. https://doi.org/10.1080/10926770903291787

Estes, M. L., \& Webber, G. R. (2021). "More Closeted Than Gayness Itself": The Depiction of Same-Sex Couple Violence in Newspaper Media. Journal of Interpersonal Violence, 36(1-2), 1-23, https://doi.org/10.1177/0886260517736271

Felitti, V. J., Anda, R. F., Nordenberg, D., Williamson, D. F., Spitz, A. M., Edwards, V., \& Marks, J. S. (1998). Relationship of childhood abuse and household dysfunction to many of the leading causes of death in adults: The Adverse Childhood Experiences (ACE) Study. American Journal of Preventive Medicine, 14(4), 245-258. https://doi.org/10.1016/s0749-3797(98)00017-8

Freeland, R., Goldenberg, T., \& Stephenson, R. (2018). Perceptions of informal and formal coping strategies for intimate partner violence among gay and bisexual men. American Journal of Men's Health, 12(2), 302-312. https://doi.org/10.1177/1557988316631965

Furman, E., Barata, P., Wilson, C.\& Fante-Coleman, T. (2017). 'It's a gap in awareness': Exploring service provision for LGBTQ2S 
survivors of intimate partner violence in Ontario, Canada. Journal of Gay \& Lesbian Social Services, 29(4), 362-77. https://doi.org/ 10.1080/10538720.2017.1365672

Grigsby, N., \& Hartman, B. R. (1997). The Barriers Model: An integrated strategy for intervention with battered women. Psychotherapy: Theory, Research, Practice, Training, 34(4), 485-497. https:// doi.org/10.1037/h0087721

Guadalupe-Diaz, X. (2013). An exploration of differences in the helpseeking of LGBQ victims of violence by race, economic class and gender. Gay \& Lesbian Issues and Psychology Review, 9(1), $15-33$.

Hardesty, J. L., Oswald, R. F., Khaw, L., \& Fonseca, C. (2011). Lesbian/ Bisexual Mothers and Intimate Partner Violence: Help Seeking in the Context of Social and Legal Vulnerability. Violence Against Women, 17(1), 28-46. https://doi.org/10.1177/1077801209347636

Hassouneh, D., \& Glass, N. (2008). The influence of gender role stereotyping on women's experiences of female same-sex intimate partner violence. Violence against Women, 14(3), 310-325. https:// doi.org/10.1177/1077801207313734

Hine, B., Bates, E. A., \& Wallace S. (2020a). I Have Guys Call Me and Say 'I Can't Be the Victim of Domestic Abuse: Exploring the experiences of telephone support providers for male victims of domestic violence and abuse. Journal of Interpersonal Violence, 088626052094455 https://doi.org/10.1177/0886260520944551

Hine, B., Noku, L., Bates E. A., \& Jayes K. (2020b). But, who is the victim here? Exploring judgments toward hypothetical bidirectional domestic violence scenarios. Journal of Interpersonal Violence, 088626052091750 https://doi.org/10.1177/0886260520917508

ILGA-Europe. (2021). ILGA-Europe's annual review of the human rights situation of lesbian, gay, bisexual, trans and intersex people covering events that occurred in Europe and Central Asia between January-December 2020. Retrieved April 14, 2021, from https:// rainbow-europe.org/sites/default/files/annual-report/AnnualReview-Full-2021.pdf

Irwin, J. (2006). Lesbians and domestic violence: Stories of seeking support. Women in Welfare Education, 8(1), 28-36.

Kitzinger, C. (2005). Heteronormativity in action: Reproducing the heterosexual nuclear family in after-hours medical calls. Social Problems, 52(4), 477-498. https://doi.org/10.1525/sp.2005.52.4.477

Liang, B., Goodman, L., Tummala-Narra, P., \& Weintraub, S. (2005). A Theoretical Framework for Understanding Help-Seeking Processes Among Survivors of Intimate Partner Violence. American Journal of Community Psychology, 36(1-2), 71-84. https://doi. org/10.1007/s10464-005-6233-6

Martin, J. L., \& Dean, L. (1987). Summary of measures: mental health effects of AIDS on at-risk homosexual men. Unpublished manuscript.

McClennen, J. C., Summers, A. B., \& Vaughan, C. (2002). Gay men's domestic violence. Journal of Gay \& Lesbian Social Services, 14(1), 23-49. https://doi.org/10.1300/j041v14n01_02

McClennen, J. C. (2005). Domestic violence between same-gender partners: Recent findings and future research. Journal of Interpersonal Violence, 20(2), 149-154. https://doi.org/ $10.1177 / 088$

McDonald, C. (2012). The social context of woman-to-woman intimate partner abuse (WWIPA). Journal of Family Violence, 27(7), 635645. https://doi.org/10.1007/s10896-012-9455-z6260504268762

Merrill, G. S., \& Wolfe, V. A. (2000). Battered gay men: An exploration of abuse, help seeking, and why they stay. Journal of Homosexuality, 39(2), 1-30. https://doi.org/10.1300/J082v39n02_01

Messinger, A. M. (2011). Invisible victims: Same-sex IPV in the national violence against women survey. Journal of Interpersonal Violence, 26, 2228-2243. https://doi.org/10.1177/0886260510383023

Messinger, A. M. (2018). Bidirectional same-gender and sexual minority intimate partner violence. Violence and Gender, 5(4), 241-249. https://doi.org/10.1089/vio.2018.0001
Meza-De-Luna, M. E., Cantera-Espinosa, M. L., Westendarp-Palacios, P., \& Palacios-Sierra, P. (2015). Never to me! Concealment of intimate partner violence in Querétaro, Mexico. Trames. Journal of the Humanities and Social Sciences, 19(2), 155. https://doi.org/ 10.3176/tr.2015.2.04

Moher, D., Liberati, A., Tetzlaff, J., Altman, D. G., \& TP Group. (2009). Linee guida per il reporting di revisioni sistematiche e meta-analisi: il PRISMA Statement. PLoS Med, 6(7), e1000097. Available at: http://www.prisma-statement.org/documents/ PRISMA\%20Italian\%20Statement.pdf

Mohr, J. J., \& Fassinger, R. E. (2000). Measuring dimensions of lesbian and gay male experience. Measurement and Evaluation in Counseling and Development, 33(2), 66-90. https://doi.org/10. 1080/07481756.2000.12068999

Murphy, C. M., \& Hoover, S. A. (1999). Measuring emotional abuse in dating relationships as a multifactorial construct. Violence \& Victims, 14(1), 39-53. https://doi.org/10.1891/0886-6708.14.1.39

Ngo, F. (2018). Same-sex and opposite-sex stalking in the United States: An exploration of the correlates of informal and formal coping strategies of the victims. International Journal of Criminal Justice Sciences, 13(1), 230-246. https://doi.org/10.5281/zenodo.1403433

Oliffe, J. L., Han, C., Maria, E. S., Lohan, M., Howard, T., Stewart, D. E., \& MacMillan, H. (2014). Gay men and intimate partner violence: A gender analysis. Sociology of Health \& Illness, 36(4), 564-579. https://doi.org/10.1111/1467-9566.12099

Owen, S. S., \& Burke, T. W. (2004). An exploration of prevalence of domestic violence in same-sex relationships. Psychological Reports, 95(1), 129-132. https://doi.org/10.2466/pr0.95.1.129-132

Page, M. J., McKenzie, J. E., Bossuyt P. M., Boutron, I., Hoffmann, T. C., Mulrow, C. D., \& Moher D. (2021). The PRISMA 2020 statement: An updated guideline for reporting systematic reviews. $B M J$, (71). https://doi.org/10.1136/bmj.n71

Potoczniak, M. J., Mourot, J. E., Crosbie-Burnett, M., \& Potoczniak, D. J. (2003). Legal and psychological perspectives on same-sex domestic violence: A multisystemic approach. Journal of Family Psychology, 17(2), 252-259. https://doi.org/10.1037/0893-3200. 17.2.252

Randle, A. A., \& Graham, C. A. (2011). A review of the evidence on the effects of intimate partner violence on men. Psychology of Men \& Masculinity, 12(2), 97-111. https://doi.org/10. 1037/a0021944

Rausch, M. A. (2016). Systemic acceptance of same-sex relationships and the impact on intimate partner violence among cisgender identified lesbian and queer individuals. Journal of Creativity in Mental Health, 11(3-4), 270-284. https://doi.org/10.1080/ 15401383.2016.1222322

Renzetti, C. M. (1989). Building a second closet: Third party responses to victims of lesbian partner abuse. Family Relations, 38(2), 157163. https://doi.org/10.2307/583669

Renzetti, C. M. (1992). Violent betrayal: Partner abuse in lesbian relationships. Sage Publications. https://doi.org/10.4135/ 9781483325767

Rinaldi, C. (2013). La violenza normalizzata. Omofobie e transfobie negli scenari contemporanei. Kaplan.

Rollè, L., Giardina, G., Caldarera, A. M., Gerino, E., \& Brustia, P. (2018). When intimate partner violence meets same sex couples: A review of same sex intimate partner violence. Frontiers in Psychology, 9, 1506. https://doi.org/10.3389/fpsyg.2018.01506

Rollè, L., Giardina, G., Caldarera, A. M., Gerino, E., \& Brustia, P. (2019). Corrigendum: When intimate partner violence meets same sex couples: A review of same sex intimate partner violence. Frontiers in Psychology, 10, 1706. https://doi.org/10.3389/ fpsyg.2019.01706

Rollè, L., D'Amico, D., Santoniccolo, F., \& Trombetta, T. (2020). News media representation of domestic violence victims and perpetrators: Focus on gender and sexual orientation in international literature. 
In S. Ramon, M. Lloyd, \& B. Penhale (Eds.), Gendered domestic violence and abuse in popular culture (Emerald studies in popular culture and gender) (pp. 149-169). Bingley (UK): Emerald Publishing Limited. https://doi.org/10.1108/978-1-83867-781-720201008

Rollè, L., Santoniccolo F., \& Trombetta, T. (2021). The help-seeking process in same-sex intimate partner violence. In T. Schackelford, The SAGE handbook of domestic violence (pp. 333-351). Thousand Oaks, California (US): SAGE Publications Ltd. https:// doi.org/10.4135/9781529742343.n21

Russell, B. (2015). Bridging the gap in knowledge about partner abuse in LGBTQ populations. Partner Abuse, 6(1), 3-7. https://doi.org/ 10.1891/1946-6560.6.1.3

Scherzer, T. (1998). Domestic violence in lesbian relationships. Journal of Lesbian Studies, 2(1), 29-47. https://doi.org/10.1300/ j155v02n01_03

Serri, F., Lasio, D., Putzu, D., \& Lampis, J. (2016). La genitorialità impossibile. Tracce di eteronormatività nei discorsi di persone attiviste omosessuali. In Everri, M. (Ed.) Genitori come gli altri e tra gli altri: Essere genitori omosessuali in Italia (pp. 79 - 100). Milano: Mimesis.

Shepard, M. F., \& Campbell, J. A. (1992). The abusive behavior inventory: A measure of psychological and physical abuse. Journal of Interpersonal Violence, 7(3), 291-305. https://doi.org/10.1177/ 088626092007003001

St. Pierre, M., \& Senn, C. Y. (2010). External barriers to help-seeking encountered by Canadian gay and lesbian victims of intimate partner abuse: An application of the Barriers Model. Violence and Victims, 25(4), 536-552. https://doi.org/10.1891/0886-6708. 25.4.536

Straus, M. A., Hamby, S. L., \& Warren, W. L. (2003). The Conflict Tactics Scales handbook. Los Angeles, CA: Western Psychological Services.
Sylaska, K. M., \& Edwards, K. M. (2015). Disclosure experiences of sexual minority college student victims of intimate partner violence. American Journal of Community Psychology, 55(3-4), 326-335. https://doi.org/10.1007/s10464-015-9717-z

Szymanski, D. M. (2006). Does internalized heterosexism moderate the link between heterosexist events and lesbians' psychological distress? Sex Roles, 54(3), 227-234. https://doi.org/10.1007/ s11199-006-9340-4

Walters, M. L. (2011). Straighten up and act like a lady: A qualitative study of lesbian survivors of intimate partner violence. Journal of Gay \& Lesbian Social Services, 23(2), 250-270. https://doi.org/ 10.1080/10538720.2011.559148

Walters, M. L., Chen, J., \& Breiding, M. J. (2013). The National Intimate Partner and Sexual Violence Survey (NISVS): 2010 findings on victimization by sexual orientation. Atlanta, GA: National Center for Injury Prevention and Control, Center for Disease Control and Prevention

Warner, M. (1991). Introduction: Fear of a queer planet. Social Text, (29), 3-17. Retrieved July 23, 2021, from http://www.jstor.org/ stable/466295

World Health Organization. (2013). Global and regional estimates of violence against women. Retrieved August 23, 2020, from https://www.who.int/reproductivehealth/publications/ violence/9789241564625/en/

Publisher's Note Springer Nature remains neutral with regard to jurisdictional claims in published maps and institutional affiliations. 